\title{
Inspirational Leadership and Its Impact On Reducing Organizational Conflict for The Staff Members at The Iraqi University
}

\author{
Souad Mohamed Rjah, Ahmed Irhayyim Abdullah* \\ Anbar Technical Institute, Middle Technical University, Iraq \\ * ahmedalfallahy@gmail.com
}

\begin{abstract}
:
The study aimed to identify the impact of inspiring leadership in reducing organizational conflicts among faculty members at the Iraqi University, by highlighting the dimensions of inspiring leadership, namely self-confidence, change management, employee empowerment, and strategic direction. This study relied on the data collected by developing a questionnaire designed for this purpose based on previous studies, distributed to (255) members of the teaching staff in colleges and scientific departments at the Iraqi University. To test the study hypothesis, multiple linear regression used. The most important findings of the study: The presence of a statistically significant effect of the four inspiring leadership dimensions in reducing the causes of organizational conflict, also that one of the most common causes of organizational conflict is the low level of cooperation between faculty members within the university. The study presented some recommendations, the most important of which are: the necessity of developing the dimensions of inspiring leadership by enhancing trust and spirit of cooperation between academic leaders and faculty members because of its direct impact in reducing the causes that lead to the occurrence of the organizational conflict. In addition, reviewing the policies that lead to non-cooperation and harmful and negative competition among them, as it is one of the leading causes of organizational conflict.
\end{abstract}

Keywords: $\quad$ Inspirational Leadership; Organizational Conflict; Change Management; Teaching Staff; Self-Confidence. 


\section{القيادة الملهمة وأثرها في الحد من الصراع التنظيمي لدى أعضاء هيئة التدريس بالجامعة العراقية \\ م.م سعاد محمد رجه، م.م. أحمد أرحيم عبدالله \\ المعهد التقني الأنبار، الجامعة التقنية الوسطى، العراق \\ *ahmedalfallahy@gmail.com}

\section{ملخص البـحث}

هدفت الدارسة التعرف على أثر القيادة الملهمة في الحد من الصراعات التذظيمية لدى أعضاء الميئة التدريسية في الجامعة العراقية، من خلال تسليط الضوء على ابعاد القيادة الملهمة وهي الثقة بالنفس، إدارة التغيير، تمكين العاملين، والتوجه الاستراتيجي. تم الاعتماد في هذه الدراسة على البيانات التي جمعت عن طريق تطوير استبانة صممت لمذه الغاية استنادًا على الدراسات السابقة، تم توزيعها على (5 5 2 ) فردًا من أعضاء الهيئة التدريسية في الكليات والاقسام العلمية بالجامعة العراقية. ولاختبار فرضية الدراسة، تم استخدام الانحدار الخطي المتعدد. أهم ما توصلت إليه الدراسة من نتائج: وجود تاثير ذي دلالة إحصائية لأبعاد القيادة الملهمة الأربعة في الحد من أسباب الصراع التنيمي، وأيضًا أن من أكثر مسببات حدوث الصراع التنظيمي هو تدني مستوى التعاون بين أعضاء الهيئة التدريسية داخل الجامعة. قدمت الدراسة بعض التوصيات من أهمها: ضرورة تنمية أبعاد القيادة الملهمة من خلال تعزيز الثقة وروح التعاون بين القيادات الأكاديمية وأعضاء الهيئة التدريسية لما لها من تأثير مباشر في الحد من الأسباب التي تؤدي إلى حدوث الصراع التظيمي. وإعادة النظر في السياسات التي تؤدي إلى عدم التعاون والتنافس الضار والسلبي بينهم كونها من اكثر الأسباب المؤدية لحدوث الصراع التنظيمي.

الكلمات المفتاحية: القيادة الملهمة، الصراع التنظيمي، إدارة التغيير، هيئة التدريس، الثقة بالنفس. Crossref doi) https://doi.org/10.51345/.v31i2.187.g176 
المقدمة:

يعيش العالم اليوم في ظل بيئة ديناميكية متسارعة، تشهد تغيرات متعددة في مختلف جوانب الحياة، وبالتالي كان لابد على المنظلات الخاصة والعامة على حدٍ سواء مواجهة هذه التغيرات بشتى الوسائل والسبل، من خلال الاهتمام بالعنصر البشري الذي يلعب دورا أساسيا في نجاح هذه المنظلات وتحقيق أهدافها، وتوفير البيئة التنظيمية الصحية والسليمة والعادلة، وذلك لإفساح المجال لإبداع العاملين ببذل قصارى جهدهم في أداء العمل المطلوب منهم. فمها تقدم العلم وتطورت التكنولوجيا، تبقى مهمة المحافظة على المورد البشري الملتزم وتطوير قابلياته من أبرز التحديات التي تواجه القيادة بشكل مستمر . (1) تعد الجامعات من المنظلات الهامة في بجال الخدمات التعليمية لأي بلد. وإن إمكانية استمرار وبقاء هذا النوع من المنظمات شأنه شأن المنظمات الأخرى يحتاج إلى الاهتحام بالقضايا الإدارية ذات البعد الاستراتيجي. حيث تتطلب زيادة معّرف الإدارات الأكاديمية، وتوفير المعرفة بالأساليب الإدارية الحديثة ذات التأثير الإيجابي في معالجة المشكلات الإدارية التي تحدث داخل المنظلات التعليمية. إنّ خصوصية عمل المنظمات التعليمية، له طابع يميزه نظراً لتعامل القيادات فيها مع العاملين الذين هم ذو مستويات تعليمية عالية، مما يجعل التعامل معهم يختلف عن المرؤوسين في منظمات الأعمال الأخرى. وبالرغم من ذلك ما يزال هناك الكثير من القضايا الإدارية التي لا يمكن التخلص منها في العمل الإداري، وعلى رأسها الصراع التنظيمي. فهو يعد احد أهم المواضيع التي تشغل فكر القيادات الأكاديمية، وذلك كون الصّراع التنظيمي لا تكاد منظمة تخلو منه، ومثلم) يُعد الصراع التنظيمي حالة صحية في بعض الأحيان، إلا أنه يجب أن لا يتعدى الحدود المرسومة له. وإن نجاح المنظمات يعتمد على كيفية التعامل معه وإدارته. وإن القدرة على التعامل معه بصورة إيجابية من أجل احتوائه، يتطلب أسلوب القيادة الملهمة، والتي تعد عنصرًا أساسيًا للمنظمات. (2) و إن أسلوب القيادة الملهمة لا يمكن أن يتم دون إيهان من قبل المديرين بأهميته ومدى فو ائده للمنظمة، حيث تعد القيادة الملهمة عامل مهم لنجاح الأعال الإدارية والتجارية في يومنا هذا، لكونها تلهم القادة للعمل 
وترفع بشكل ملحوظ مستويات الأداء الفردي والجماعي وتوقد الإبداع والابتكار الجريء، أي إنها تُفتح إمكانات كامنة من خلال الاستفادة من دوافعنا وقيمنا الداخلية و إلهام الآخرين لمتابعة شغفهم والتحرك نحو أهداف طموحة، وغالبًا ما يحتاج الأمر إلى تنمية المرؤوسين ورفع قدراتهم ومهارتهم لحل المشكلات ومو اجهة المواقف وتقبل التّحدي.(3) لذا تأتي هذه الدراسة محاولة للتعرف على دور القيادة الملهمة في الحد من زيادة الصراع التنظيمي عن الحد المرغوب فيه من قبل القيادات الأكاديمية.

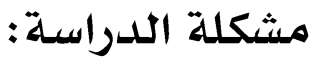

تتمثل مشكلة الدراسة الحالية من خلال الاحتكاك بالمشكلة بشكل فِعليّ، وملاحظة وجود الصراعات التنظيمية في الجامعات بشكل عام وفي كليات الجامعة العراقية بشكل خاص، وهذا ما أبداه أَعضَاء الهيئة التدريسية من خلال اللقاءات المباشرة معهم بخصوص هذا الموضوع. كذلك أن النجاح في التعامل مع الصراع التنظيمي يحتاج بالضرورة إلى قيادة إدارية متفتحة، وبعيدة عن الأساليب التقليدية، وخصوصاً عندما يكون التعامل مع أفراد يتمتعون بدرجات علمية عالية، كأعضَاء هيئة التدريس في الجامعة. وتأسيساً على ذلك، تمثلت مشكلة الدراسة في محاولة التعرف على أثر القيادة الملهمة في الحد من الصراع التنظيمي لدى أعضاء الهيئة التدريسية بالجامعة العراقية، وذلك من خلال الإجابة عن الأسئلة التالية: 1 - هل نمط القيادة الملهمة قادر على مو اجهة الصر اعات التنظيمية داخل الجامعة العراقية؟ 2- ما هي طبيعة تأثير أبعاد القيادة الملهمة (الثقة بالنفس، إدارة التغير، تمكين العاملين، التوجه الاستراتيجي) في الحد من الصراع التنظيمي بالجامعة العراقية؟ 3- هل أن أبعاد القيادة الملهمة متساوية في الحد من الصراع التنظيمي؟ 4- ما مدى تو افر ابعاد القيادة الملهمة (الثقة بالنفس، إدارة التغير، تمكين العاملين، التوجه الاستراتيجي) لدى أعضاء الهيئة التدريسية بالجامعة العراقية؟ 


\section{أهميلة الدراسـة:}

تنبثق أهمية هذه الدراسة من خلال أهمية المتغيرات التي تبحث فيها (القيادة الملهمة والصراع التنظيمي)، وذلك لما لهذه المفاهيم من أثر هام في تحسين أداء المنظلات وتطويره، وكذلك لكونها تعد من الموضوعات الإدارية التي لا تزال تَلقى اهتحام كبير من قبل الباحثين، حيث إن نجاح وتطور المنظلات، يرتكز بشكل أساسي على قيادتها وما تمتلكه من إبداع ودراية في تسيير أعحالها. كما وتستمد الدراسة أهميتها من كونها تربط القيادة الملهمة بمشكلة إدارية يو اجهها المديرون يوميًا في متابعة أعلاهم الإدارية، ألا وهي مشكلة الصراع التنظيمي، وما ينتج عنه من سلبيات، إذا زاد عن الحد المرغوب فيه في منظمات الأعحال. حيث تبذل القيادات الإدارية جهود كبيرة من أجل معالجتة، والحد من تأثيراته السلبية على بيئة العمل، وعلى رأسها إعاقة تحقيق الأهداف

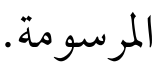

وتكمن الأهمية النظرية للدراسة بها ستضيفه إلى الرصيد في ججال أدبيات القيادة الملهمة، والصراع التنظيمي، نظراً لندرة الدراسات التي تعالج هذا الموضوع المهم في قطاع المؤسسات التعليمية في العراق بشكل خاص. إذ يمكن أن تساهم في تقديم إطار نظري متكامل يثري المكتبة الإدارية في الموضوعات التي تبحث فيها.

\section{أهـداف الدراسـة:}

للإجابة على تساؤ لات الدراسة وحل مشكلتها سعى الباحثان لتحقيق الأهداف التالية: 1 - التعرف على واقع الصراع داخل الجامعة العراقية من وجهة نظر أعضاء هيئة التدريس. 2- الكشف عن أثث القيادة الملهمة في الحد من الصراع التنظيمي بالجامعة العراقية. 3- التعرف على أكثر أبعاد القيادة الملهمة تأثيرًا في الحد من الصراع التنظيمي. 4- التعرف على مدى تو افر ابعاد القيادة الملهمة (الثقة بالنفس، إدارة التغير، تمكين العاملين، التوجه الاستراتيجي) لدى أعضاء الهيئة التدريسية بالجامعة العراقية. 


\section{فروض الدراسة:}

استكمالاً لمشكلة البحث ووأهدافها، تم صياغة الفراسهات أنمات التالية:

الفرضـــية الرئيســية الأولـى Ho: عدم وجود أثر ذو دلالة إحصائية لعناصر القيادة الملهمة (إدارة التغيير، الثقة بالنفس، تمكين العاملين، التوجه الاستراتيجي) في الحد من الصراع التنظيمي لاعضاء الهيئة التدريسية بالجامعة العراقية عند مستوى الدلالة (a 0.05$).$ الفرضية الرئيسية الثانية H1: يوجد أثر ذو دلالة إحصائية لعناصر القيادة الملهمة (إدارة التغيير، الثقة بالنفس، تمكين العاملين، التوجه الاستراتيجي) على الصراع التنظيمي لاعضاء الهيئة التدريسية بالجامعة العراقية عند

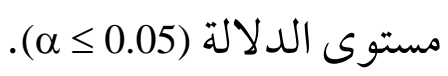

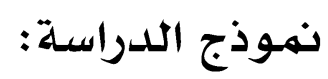

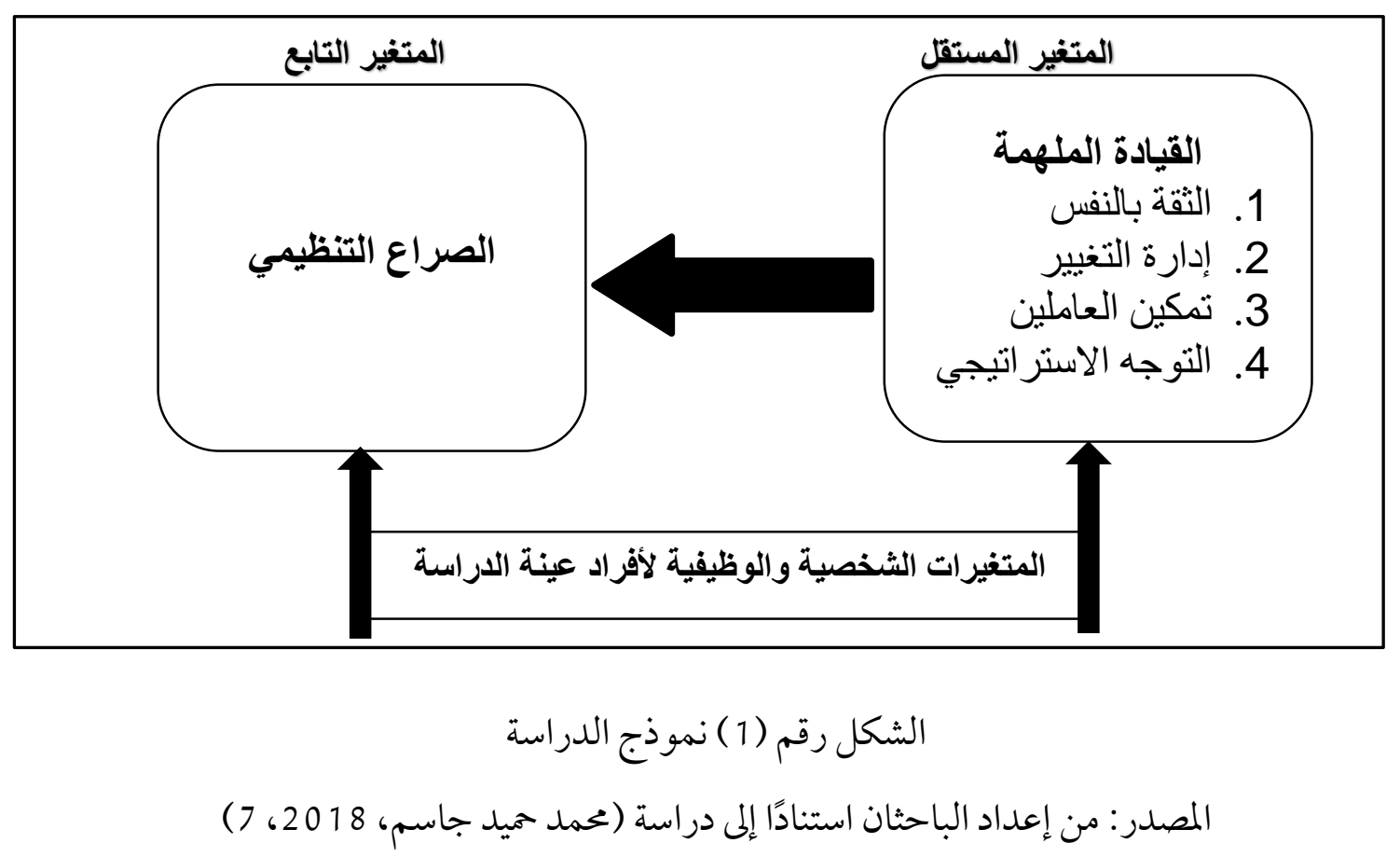




\section{منهجية الدراسةة:}

استُخدم في هذه الدراسة المنهج الوصفي التحليلي في جمع البيانات والمعلومات اللازمة لإتمامها، الذي يعتمد على العرض الوصفي لمتغيرات الدراسة، وهما أبعاد القيادة الملهمة، والصراع التنظيمي. وذلك بالاعتماد على مصدرين في جمع هذه البيانات والمعلومات، الأول المصادر الثانوية: وتتمثل في المسح المكتبي والأدبيات الإدارية الباحثة في موضوعي القيادة الملهمة والصراع التنظيمي. والثاني المصادر الأولية: وتتمثل في البيانات التي تم جمعها من مصادر عينة الدراسة بالاعتماد على أداتها.

\section{مجتـهـع الدراسـة وعينتهـا:}

يتكون بجتمع الدراسة من أعضاء هيئة التدريس في كليات الجامعة العراقية من (مدرس، أستاذ مساعد، أستاذ)، إذ يبلغ إجمالي عددهم وفقا للاحصائيات المنشورة بالموقع الرسمى للجامعة العراقية (754) عضو هيئة تدريس، والجدول رقم (1 ) يوضح بيان تفصيلي بتوزيعهم من حيث العدد و النوع والدرجة العلمية.

جدول رقم (1) أعداد أعضاء هيئة التدريس بالجامعة العراقية

\begin{tabular}{|c|c|c|c|}
\hline \multirow[t]{2}{*}{ الجموع } & \multicolumn{2}{|c|}{ الجموع } & \multirow{2}{*}{ اللقب العلمي } \\
\hline & 1 & ذكور & \\
\hline 141 & 19 & 122 & أستاذ \\
\hline 318 & 80 & 238 & أستاذ مساعد \\
\hline 295 & 108 & 187 & مدرس \\
\hline 754 & 207 & 547 & الجمموع \\
\hline
\end{tabular}

قد بلغت عينة الدرسة (25 25 ) عضو هيئة تدريس، والتي تم تحديد حجمها الكترونيا من خلال موقع ( Survey (Monkey (255) استبانة على أعضاء هيئة التدريس بالجامعة العراقية، تم استرداد (216) استبانة، وتم حذف (6) 
استبيانات لاحتوائها على العديد من القيم المفقودة، وبذلك تكون عدد الاستبيانات الخاضعة للتحليل الاحصائي هي (210) استبانة أى بنسبة (2.3\%)، والجدول رقم (2) يبين عدد الاستبانات الموزعة والمستردة والصالحة للتحليل الإحصائي.

جدول رقم (2) الاستبانات الموزعة والمستردة والصالحة للتحليل

\begin{tabular}{|c|c|c|c|c|c|c|}
\hline \multicolumn{6}{|c|}{ الاستبا ت } & المنظمة \\
\hline نسبة التالفة & المستزبة وغير & الاستجابة & المستجيبة & المستزدة & الموزعة & الثدريس لجامعة هيئة \\
\hline$\% 17.7$ & 45 & $\% 82.3$ & 110 & 216 & 255 & العراقية \\
\hline
\end{tabular}

ولحساب حجم العينة يدويا سيكون من خلال استخدام معادلة ريتشارد جيجر التالية: Sample size $=\frac{\left(\frac{z}{d}\right)^{2} \times(0.50)^{2}}{1+\frac{1}{N}\left[\left(\frac{z}{d}\right)^{2} \times(0.50)^{2}-1\right]}=255$

$$
\begin{aligned}
& \text { (754) = N } \\
& \text { 年 }=\mathbf{n} \\
& \text { } 0.96 \text { = Z } 1.96 \text { الدرجة المعيارية المقابلة لمستوى المعنوية 0.05، وعند الثقة } 0.9 \\
& 0.05=\mathbf{d}
\end{aligned}
$$

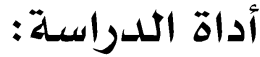

تم تصميم استبانة خاصة لجمع البيانات اللازمة هذه الدراسة، وبالاعتماد على استبانات الدراسات السابقة ذات العلاقة بموضوع الدراسة. وقد تضمنت ثلاثة أجزاء، اختص الجزء الأول بالأسئلة المتعلقة بالمعلومات الشخصية والوظيفية لأفر اد العينة والتي تتضمن (5 ) أسئلة. بينما اختص الجزء الثاني بالمتغير المستقل والمتعلق 
بقياس أبعاد القيادة الملهمة حيث تضمنت (21 ) عبارة، وهي تقيس الأبعاد الأربعة للقيادة الملهمة، وتم أستخدام مقياس ليكرت الخحاسي للإجابة عن عبارات هذا الجزء (غير موافق بشدة، غير موافق، محايد، موافق، موافق بشدة). أما الجزء الثالث، فقد خُصص للمتغير التابع وقياس واقع الصراع التنظيمي حيث تضمنت (8) أسئلة. وتم اعتماد أيضا مقياس ليكرت الخماسي للإجابة عن أسئلة هذا الجزء. و الجدول رقم (3) يوضح ذلك. جدول رقم (3 ) مقياس ليكرت الخماسي

\begin{tabular}{|c|c|c|c|c|c|}
\hline موافق بشدة & موافق & محايد & غير موافق & غير موافق بشدة & الاستجابة \\
\hline 5 & 4 & 3 & 2 & 1 & الدرجة \\
\hline
\end{tabular}

\section{صدق وثبـات أداة الدراسـة:}

تم التأكد من صحة الاستبانة في جمع المعلومات بواسطة الصدق الظاهري وذلك بعرضها على لجنة من المحكمين لمر اجعة كل فتر اتها والتأكد من تغطية الاستبانة لجميع الجو انب التي تتعلق بمتغيرات الدراسة حتى وصولها لهذا الشكل النهائي. أما فيما يتعلق بثبات فقرات الاستبانة تم التأكد بواسطة اجراء اختبار الفا كرونباخ (alpha Cronbach's) للثبات. وتم بيان النتائج كما يلي: بلغت قيمة الفا كرونباخ لجميع فقرات الاستبانة (20 0 (9 0 )، وبلغت قيمة أبعاد القيادة الملهمة الثقة بالنفس ، إدارة التغيير، تمكين العاملين ، والتوجه الاستراتيجي (0.855)، وقيمة الصراع التنظيمي (0.866)، نجد أن جيع القيم اعلى من (0.7) وذلك يؤكد ثبات المقياس وانه يمكن الاعتحاد عليه لاجر اء الدراسة.

\section{أساليب التحليل الاحصائي:}

تمت معالجة البيانات عن طريق استخدام بعض الأساليب الإحصائية الملائمة للدراسة، واختبار الفرضيات. فقد تم استخدام التكرارات والنسب المئوية لوصف الخصائص الشخصية لأعضاء هيئة التدريس عينة الدراسة، كما تم استخدام الوسط الحسابي والانحر اف المعياري لبيان مدى تركز وتشتت إجابات أفراد العينة عن عبار ات الدراسة، فيها تم اعتماد الانحدار الخطي المتعدد لاختبار فرضية الدراسة. 


\section{الدراسـات السـابقة}

من خلال المسح الذي أُجري، تم التوصل إلى مجموعة من الأدبيات الإدارية التي بحثت في موضوع الدراسة، حيث نلاحظ من خلال مراجعة واستعر اض هذه الدراسات أنه يمكن تقسيمها إلى ثلاث بجموعات، وذلك على النحو التالي: n n 1 - دراسات ركزت على متغير القيادة الملهمة من حيث أثره في العديد من المتغيرات الأخرى: دراسة (كامل، مهدي، وكمونة، 2019)، بعنوان (القيادة الملهمة ودورها في تحقيق التميز التنظيمي دراسة إستطلاعية في المدراس الإعدادية الحكومية في مدينة كربلاء)، تناولت الدراسة القيادة الملهمة ودورها في تحقيق التميز التنظيمي، حيث هدفت إلى التعرف على الواقع الفعلي للأبعاد القيادية في المدارس المبحوثة ودور المدير كقائد ملهم للآخرين من أعضاء الهيأة التدريسية من خلال بعض السلوكيات التي تؤدي إلى تحقيق التميز المدرسي. وخلصت الدراسة إلى وجود علاقة إرتباط ذات دلالة إحصائية موجبة بين المتغيرات (القيادة الملهمة والتميز التنظيمي). حيث أوصت الدراسة لضرورة توظيف أبعاد القيادة الملهمة بالمدارس المبحوثة لغرض تطويرها وذلك من خلال أجراء تغيرات على الملمارسات والطرائق المستخدمة في التدريس من قبل أعضاء الهيأة التدريسية، والاعتراف بالمدير كأداة للتغير من خلال العمل الفرقي. دراسة (Awad,2018)، بعنوان (العلاقة بين القيادة الملهمة وريادة الأععال في الشركات الصغيرة والمتوسطة في قطاع غزة: دراسة تطبيقية في قطاع الملابس)، وضحت هذه الدراسة أن القيادة الملهمة تستطيع تقديم الصورة المثلى لملمارسة الأنشطة الادارية وذلك من خلال تفاعل الادارة مع افراد المنظمة لتحقيق الأهداف المشتركة لهم. حيث سعت الدراسة لفهم هذا المتغير من خلال ربطه بقطاع ريادة الاعمال، إذ هدفت الدراسة للوصول الم التفسير الامثل لتوضيح العلاقة مابين القيادة الملهمة وريادة الأعمال في الشركات الصغيرة والمتو سطة العاملة في بجال صناعة الملابس بقطاع غزة، وخلصت الدراسة الى وجود علاقة طردية قوية مابين متغيرى الدراسة. حيث أوصى الباحث بضرورة تعزيز مبادىء القيادة الملهمة فى قطاع ريادة الأعال ، وكذلك الحث على ضرورة زيادة عدد الأبحاث المتعلقة بنظرية القيادة الملهمة. 
دراسة (العيساوي، 2018 )، بعنو ان (القيادة الملهمة وأثرها على الالتزام التنظيمي لدى الموظفين في وزارة الصناعة والتجارة الأردنية)، هدفت الدراسة التعرف على أثث تطبيق القيادة الملهمة بأبعادها (الثقة بالنفس، و الرؤية المستقبلية، والاعتراف به كأداة للتغيير، والحساسية تجاه القيود البيئية) على الالتزام التنظيمي لدى الموظفيين في وزارة الصناعة والتجارة الأردنية، حيث توصلت الدراسة الى إن واقع اهتحام المسؤولين بالقيادة الملهمة كانت بمستوى تقدير متوسط. ومستوى الالتزام التنظيمي لدى الموظفين جاء بمستوى تقدير متوسط. وتبين وجود أثر للقيادة الملهمة ببعديه (الرؤية المستقبلية، والحساسية تجاه القيود البيئية) على الالتزام التنظيمي لدى الموظفين في وزارة. أوصت الدراسة بضرورة تشجيع القيادات الإدارية في الوزارة على العمل بالمفاهيم الحديثة في الإدارة واستعم|لها كأسلوب اداري في عملهم اليومي من خلال نشر ثقافة القيادة الملهمة بأطر عملية تدعم التطبيق تلقائيًا. در اسة (Bonau, 2017)، بعنو ان (كيف تصبح قائد ملهم. وماذا لتجنبها)، هدفت الدراسة تحليل الجوانب النظرية للقيادة الملهمة وتقديم الخطوات العلمية لتطبيق نظرية القائد الملهم. حيث كانت ابعاد القيادة الملهمة (الرؤية، الاصالة، الوعي الذاتي)، ومن خلال مقارنة وجهات النظر المختلفة حول نظرية القيادة الملهمة توصلت الدراسة إلى أن الوعي الذاتي والأصالة هي الأسس الرئيسية التي يتبعها القائد الملهم لتنفيذ رؤية مشتركة. حيث يتم تقديم أداة للتنفيذ العملي التي تسمح للقادة قياس الخصائص المختلفة للقيادة الملهمة وتقييم التقدم المحرز في هذا المجال. در اسة (Rao, 2015)، بعنو ان (حالة القيادة الملهمة في بيئة الموارد البشرية للألفية الجديدة)، هدفت الدراسة التعرف على بيئة المو ارد البشرية الديناميكية ووضع القيادة المهمة فيها، حيث خلصت الدراسة الى أن يتمتع القادة الملهمون بالمرونة الكافية للتكيف مع بيئة الموارد البشرية المتغيرة. بل وإنهم يتوقعون المسار المحتمل للبيئة المستقبلية بذكائهم. وأيضًا إن القيادة الملهمة هي متطلب ضروري لإِلام الاتباع والفرق والموظفين، وأن العالم شهد إخفاقات على مستوى القيادة أكثر من نجاحها، إن أي قيادة أقل من القيادة الملهمة هي فقط قيادة عادية أو اسوء من ذلك وهي صيانة إدارية. أوصت الدراسة إدارات ومديري الموارد البشرية 
التعامل مع التحديات التي تواجهها بيئة الموارد البشرية من خلال بناء الكفاءات والقدرات والمواهب اللازمة.

• دراسة (خليف، ومحمد 14 20)، بعنوان (القيادة الملهمة والمفاجأة الإستراتيجية، دراسة استطلاعية لأراء عينة من القيادات الإدارية في عدد من دوائر محافظة نينوى)، قدمت الدراسة إطار فكري عن متغير القيادة

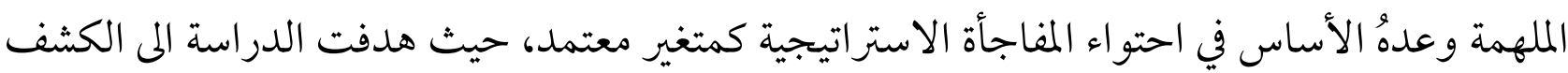
عن درجة الارتباط والاثر بين الخصائص القيادية والمفاجأة الإستراتيجية من خلال الوقوف على حقيقتها في ظل المؤشرات المعبرة عنها في المنظمات. خلصت الدراسة المى أن وجود درجة من الارتباط الإيجابي بين صفات القيادة الملهمة وبين مؤشرات المفاجأة الاستراتيجية على المستويين الكلي والفرعي مما يوفر انطباعا بأن الخصائص الإيجابية للقيادة الملهمة قد تكون عوامل دفع مثلما هي مجسات تحسس بأية احداث

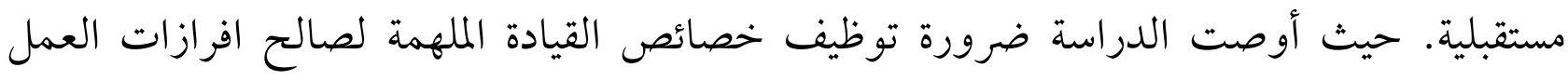
واجهاضات البيئة وعلى نحو ييعلها متسعا لاحتواء اية مفاجأت في ميدان مساحته الاستعداد وعمق

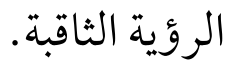

2- دراسات بحثت في متغير الصراع التنظيمي من حيث أثره أو تأثره بعدد من المتغيرات الأخرى: دراسة (حريم، 2003)، بعنوان (إدارة الصراع التنظيمي: دراسة ميدانية على قطاع المصرفي في الأردن)، هدفت الدراسة التعرف على أساليب إدارة الصراع التنظيمي المستخدمة في المصارف التجارية الأردنية، وتحديد أي من الأساليب اكثر تطبيقاً، وما إذا كانت الفروق في مدى تطبيق الصراع الأساليب تعزى لعوامل

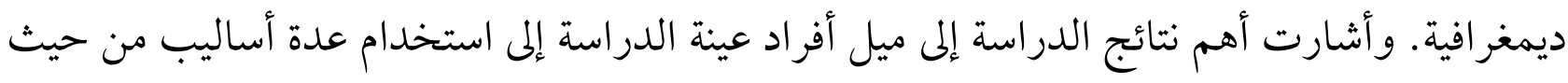
مدى التطبيق: التعاون، الإجبار، التهرب. كما أشارت النتائج إلى وجود فروق في مدى تطبيق الأساليب المذكورة، تُعزى لعو امل: المستوى الوظيفي، والمؤهل العلمي، والعمر، وسنوات الخهبرة المبرة.

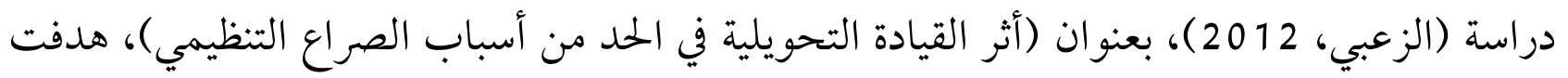
الدراسة التعرف على تأثير القيادة التحويلية في الحد من أسباب الصراع التنظيمي في جامعة العلوم 
التطبيقية الخاصة. حيث حددت أربعة أسباب للصراع التنظيمي وهي: محدودية الموارد، عدم وضوح الصلاحيات، عدم وضوح المسؤوليات، وتعارض الأهداف. خلصت الدراسة الى وجود تأثير ذي دلالة إحصائية لأبعاد القيادة التحويلية في الحد من الصراع التنظيمي. وأيضًا أن أكثر الأسباب المؤدية إلى حدوث الصراع هي محدودية الموارد. وعليه أوصت الدراسة بضرورة إعادة النظر في السياسات التي تؤدي إلى محدودية الموارد كونها أكثر الأسباب المؤدية لحدوث الصراع التنظيمي. دراسة (الحديدي، 14014 )، بعنوان (الصراع التنظيمي)، هدفت الدراسة لإيجاد العلاقى بين أنواع الصراع التنظيمي وأساليب إدارته وتطوير إطار شمولي لإدارة أنواع الصراع وتحقيق أفضل إستثمار للجانب الإيجابي فيه، وتحجيم فرص تفاقم الصراع السلبي فيه، وتعريف الباحثين بتماثل أو اختلاف مواقع الصراع على مستوى المنظلات. إذ خلصت الدراسة إن الصراع التنظيمي مسألة ناجمة عن التفاعل الاجتماعي والعلاقات الشخصية بين الأفراد والجماعات، والتي يكون لها تأثير كبير ومباشر على نشاط المنظمة وسير أعحالها وتطويرها وتحقيق أهدافها، ومن هنا أوصت الدراسة بضرورة الإلمام والمعرفة التامة بأساليب إدارة الصراع بالشكل الذي يخدم أهداف ومصالح المنظمة والأفراد العاملين فيها. دراسة (عبد الواحد، 2008)، بعنوان (الأساليب المتبعة في إدارة الصراع التنظيمي داخل المنظمات غير الحكومية في قطاع غزة من وجهة نظر المدراء)، هدفت الدراسة التعرف على أثر المتغيرات الشخصية كالسن، الجنس، والمؤهل العلمي، على أساليب إدارة الصراع في المنظمات غير الحكومية، من خلال دراسة مفهوم الصراع وأسبابه وآثاره الإيجابية والسلبية. إذ خلصت الدراسة إلى أن هناك أثراً واضحًا للمتغيرات الشخصية على إتباع المدراء لأساليب إدارة الصراع، وأيضًا عدم إدر اكهم لأهمية الصراع التنظمي واعتباره معول هدم لا أداة بناء. أوصت الدراسة بضرورة زيادة وعي المدراء وتعميق فهمهم لأهمية الصراع التنظيمي وأساليبه المختلفة، وتعريفهم بالحالات التي يمكن فيها استخدام الأسلوب الأنسب حسب الظروف والمعطيات التي يتعامل معها. 
دراسة (راشد، 2017)، بعنو ان (ستراتيجيات إدارة الصراع التنظيمي وانعكاساتها في الأداء الوظيفي)، هدفت الدر اسة التعرف على ستراتيجيات إدارة الصراع التنظيمي والتي شملت (مفهوم الصراع وتطوره، أنواع الصراع التنظيمي، ستراتيجيات أدارة الصراع التنظيمي)، وانعكاساتها وتأثيرها على الأداء الوظيفي، وقد تم اختيار مستشفى الرشاد التدريبي التابعة إلى دائرة صحة بغداد للتطبيق، حيث بلغت عينة البحث (100) ممرض وممرضة. خلصت الدراسة إلى أن الصراع يعد ظاهرة تنظيمية حتمية في المستشفى وأن وجود مستوى مقبول منه أمر ضروري لمواصلة الحياة التنظيمية. وايضًا لا يمكن أن يعد الصراع سلبيا دائما او أيجابيا دائما فالحكم عليه يمكن تحديده من خلال قدرة أدارة مستشفى الرشاد على أدارته بشكل صحيح. أوصت الإدارة بضرورة توجية أدارة الصراع ليكون أكثر إيجابية في أطار الأهمية البالغة لعملية إدارة

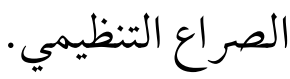
دراسة (قدوري، ومحمود، 2019)، بعنوان (دور استراتيجيات إدارة الصراع التنظيمي في تعزيز سلوك العمل)، هدفت الدراسة إلى بيان دور استراتيجيات إدارة الصراع التنظيمي في تعزيز سلوك العمل لدى عينة مختارة من المنظلات الصحية في البيئة العراقية، وإن الأساس الفكري للدراسة يتمثل في أن الربط بين ابعاد استراتيجيات إدارة الصراع التنظيمي وسلوك العمل تدفع نحو تهيئة بيئة عمل مناسبة تعزز من السلوك الإيجابي للعمل في المنظمات الصحية، خلصت الدراسة إلى إن استراتيجيات إدارة الصراع التنظيمي ها علاقة ارتباط وتأثير معنوية عالية في تعزيز سلوك العمل، أوصت الدراسة بضرورة تبني المنظمات الصحية آليات واساليب استراتيجية تستند إلى تفعيل دور استراتيجيات إدارة الصراع التنظمي من اجل ايجاد بيئة دافعة وإييابية لسلوك العمل. 3- دراسات تناولت أثثر متغير القيادة الملهمة في الحد من الصراع التنظيمي: دراسة (صالح، 160 ) )، بعنوان (أثث أبعاد القيادة الملهمة في الحد من التوتر التنظيمي)، هدفت الدراسة لتسليط الضوء على السعي بصدق للتحقق من أفعال الآخرين، الثقة والاعتمادية، القدرة على تمكين العاملين، الانصات الجيد للمرؤوسين "التابعين"، التوجيه لتنمية رؤية مشتركة. خلصت الدراسة إلى أن 
هناك قصور في تقييم جهود العاملين من قبل الإدارة فيما يخص التميز بالأداء، الأمر الذي يزيد من التوتر التنظمي. أوصت الدراسة بضرورة إيجاد طرق لتقيم أداء العاملين كل حسب إنجازه ليكون ذلك دافعاً لهم نحو إنجاز أكبر وعدم غض النظر عن أدائهم المتميز محا يجبط الإنجاز لديهم.

\section{ما يميز هذه الدراسة عن الدراسـات السابقة}

من خلال استعر اض الدراسات السابقة نلاحظ أن هذه الدراسة تتميز عن الدراسات السابقة بتركيزها على الفجوة البحثية المتعلقة بأنها تبحث في (مدى إسهام القيادة الملهمة في الحد من الصراع التنظيمي)، حيث نلاحظ بأن جميع الدراسات السابقة التي تم استعر اضها قد تناولت أثر القيادة الملهمة على متغيرات أخرى غير متغير الصراع التنظيمي كدراسة أثر القيادة الملهمة في (تحقيق التميز التنظيمي، ريادة الأعمال في الشركات، بيئة الموارد البشرية، والمفاجأة الإستراتيجية، والالتزام التنظيمي)، باستثناء دراسة (صالح، 2016) التي درست أثر أبعاد القيادة الملهمة في الحدد من التوتر التنظيمي. كا تتميز هذه الدراسة من حيث مجتمع دراستها الذي تَكون من أعضاء الهيئة التدريسية في الجامعة العراقية، في حين تمت الدراسات السابقة في بيئات تنظيمية مختلفة عن البيئة التنظيمية للدراسة، التي لا تعطي نتائجها مؤشرات علمية يمكن تعميمها على بيئة الجامعة العراقية.

\section{المبحث الأول : الإطار النظري والمفاهيمي للدراسـة}

تو اجه المنظلات العديد من التحديات والصعوبات التي تُولد على المجتمع والمنظمة وأفر ادها ضغطًا لتحمل مسؤوليات وأعباء استثنائية، وعليه ظهرت الحاجة إلى كيفية توظيف وإبراز السمات القيادية في احتواء ما ينجم عن الصراع التنظمي داخل المنظمة. (4) إذ يعتمد نجاح أي منظمة على كفاءة قيادتها في العملية الإدارية، حيث يقع على عاتقها مسؤولية تحقيق الأهداف المتعلقة بالمنظمة، لذلك يعتبر نمط القيادة الملهمة الذي يتسم به القائد العامل الرئيس في توجيه مسار المنظمة، وتطوير أدائها، وكذلك غالبًا ما يُظهر اثره في سلوك الموظفين، وأدائهم بشكل فعال، كما ينعكس على مستوى روحهم المعنوية، ورضاهم عن العمل من خلال تحقيق أهداف 
الطرفين. (5) وتأسيسًا على ذلك ينطلق هذا الإطار من الخلفية الفكرية لمتغيري الدراسة مثثلا بــ(القيادة الملهمة، و الصراع التنظيمي) وعلى وفق السياق الآتي:

\section{أولاً: القيادة الملههمة}

\section{1- مفهوم القيـادة الملههمة}

يعود جذور هذا المفهوم إلى المصطلح (Charisma) المستمد من اللغة اللاتينية وتعني الإلهام أي القوى التي يصعب تفسيرها بوضوح من خلال الوسائل المنطقية، (6) حيث كان هناك اهتحام متزايد بنوع من نظريات القيادة التي تتقاسم الر أي القائل بأن "القادة المتميزين يتعدون معاملات الأداء البسيطة مقابل مكافاة، ويكون لهم تأثير عميق على أتباعهم ومنظلتهم"، بها في ذلك القدرة على أن يكونو اقوة رئيسة في تحقيق رؤى وتغييرات جديدة، فأطلقت تسميات متنوعة لوصف هؤلاء القادة، بها في ذلك التحويلية والرؤيوية. (7) ومع ذلك، فإن الإلهام يكمن في جوهر ما تقترحه هذه النظريات من حيث التميز البارع في الدور القيادي. وقد يعبر القادة الملهمون عن رؤية تستند إلى القيم الأيديولوجية القوية التي تجعل من التابعين ينشطون ويتو افقون معها، أي قدرتهم على ترسيخ وتعزيز الثقة لدى تابعييهم وبدرجة عالية، فضلًا عن إثارة الدافع الجوهري. (8) انسجاما مع ما سبق نورد بعض التعاريف التي تخص القيادة الملهمة استنادًا إلى اراء بعض الباحثين المهتمين في هذا المجال إذ يُعرفها (توماس Thomas) بأنها تمثل قدرة حصول الفرد على تأييد وثقة من حوله من الأفراد بالإضافة إلى قدرته على تحفيزهم و إلهامهم للوصول إلى أشياء عظيمة. (9) عرفت (جويس Joyce) القيادة الملهمة بأنها أحد أنحاط القيادة التي تتطلب من القائد ان تتو افر لدية الإرادة والعزيمة التي تجعله يفكر دائًا في المرؤوسين، ويوليهم الاهتمام الأكبر قبل التفكير في نفسه، بجانب قدرته على توجيهم نحو تحقيق الأهداف، والمبادرة، والإبداع، و الفاعلية، والاعتراف بالخطأ عند وقوعه، والمرونة للتغيير عندما يحتاج الأمر إلية. (10) 
وأخيرًا عرفها (جيرالد وبارون Jerald \& Baron) بأنها تلك القيادة التي تحقق نجاحات غير عادية من خلال إحداث تغيرات في نفوس المرؤوسين في العمل وجعلهم يقومون بأعمال غير عادية عند مواجهة تغييرات في

بيئة العمل. (11) (11) بناءُ على ما تقدم يمكن القول إن اختلاف التعاريف مرده المى اختلاف وجهة نظر كل باحث ومنطلقاته الفكرية والأيديولوجية.

\section{2- أهمية القيادة الملهمة}

تتضمن أهمية القيادة في الربط المباشر للموظف بوظيفته، ولذلك فإن للقيادة دورًا مؤثرًا في التزام أو عدم التزام الموظف أو ضعف علاقته بوظيفته ومنظمته، ويعتبر نمط القيادة الملهمة من العوامل التنظيمية المؤثرة في الالتزام التنظيمي للأفراد، حيث يعمل ذلك النوع من القيادة على تعزيز الالتزام وتطويره لديهم، ويلعب القائد دورًا فعالًا من خلال إقناع الاخرين بضرورة إنجاز الأععال بفعالية وفي جو عمل مناسب. (12) تمكن أهمية القيادة الملهمة وفق ما تناوله العديد من الباحثين في عدة نقاط، حيث قام الباحثان بتجميعها كالآتي:(13) 1 - إن توافر القيادة الملهمة في المنظمة يؤثر إيبابيًا في تو افر السلوكيات الأخلاقية للعاملين. 2- إن للقيادة الملهمة أثراً إيجابيًا في الكفاءة التنظيمية والتوافق التنظيمي بين الفرد والعمل. 3- تقوم على دعم القوى الإيجابية في المنظمة المتوفرة لدى المرؤوسين وتقليص الجو انب السلبية والحد منها. 4 - السيطرة على المشكلات المتولدة في العمل وحلها، وحسم الخلافات والآراء بين الافر اد. 5 - إن القائد الملهم لديه القدرة على تكوين رؤية مشتركة بينه وبين العاملين فهو يمثل حلقة الوصل بين المنظمة والعاملين بها، ومن خلال هذه الرؤية المشتركة يستطيع تحفيز العاملين وبث روح النشاط والحيوية لديهم مما ينعكس إيجابيًا على المنظمة. 


\section{3- أبعاد القيادة الملهمـة}

إن التمييز في أبعاد القيادة من أهم عناصر العمل الإيجابي، الذي جاء نتيجة الاستثمار الفاعل لها من قبل تلك القيادات، (14) حيث تهدف إلى التأثير في سلوك الموظفين، وتنسيق جهودهم وعلاقاتهم، وتعزيز الروح المعنوية والإلهام في قادتهم، وبناء توجهاتهم نحو الأفضل بها يكفل تحقيق الأهداف المرجوة. (15) سوف نتناول الأبعاد الآنفة الذكر والتي جاء بها كل من (جيرالد ويارون Jerald \& Baron) حيث حدداها بأربعة أبعاد أساسية للقيادة الملهمة والتي سيتم تناولها في الجانب التطبيقي كونها أهم المرتكزات التي جاءت بها الدراسة، وهي كالآتي:

أ. الثقة بالنفس

تُعد من المكونات الأساسية للشخصية السوية، وهي أساس كل نجاح وإنجاز تُريد أن تنجزه. إذ تمثل قدرة القائد وثقته في السيطرة على المشكلات.(16) وهذا يعني أن لا يوجد قائد مزعزع الثقة (ثقة القائد بقدراته ومبادئه) وهي نابعة من القدرة التي يمتلكها وصحة الاحكام التي يطلقها الى حد أن يكون الآخرون لديهم تصور عنه. ب. ب إدارة التغيير

يعد التغيير مسالة أساسية لكل منظمة أو دولة في مختلف مفاصلها الإدارية، وهو العنصر الحتمي في كافة مراحل النشاط الإداري، وترتبط عملية نجاحه ارتباطاً وثيقاً بمواكبة الأحداث والتطورات التي تحصل حياله،(18) حيث يصاحب التغيير مقاومة كبيرة على الرغم من أنه شيء مطلوب وحتمي لتطوير المنظمة وتقدمها، والقائد الملهم له القدرة والدور كبير في التعامل مع تلك المقاومة من خلال أقناع المرؤوسين بأن التغيير يعد شيئا قائما وبدونه يستحيل التقدم، وهذا يقودنا إلى ظهور مشكلة كُره التغيير تواجه المؤسسة من قبل الموظفين حيث لا يرغبون في التغيير ويقابله شي من المقاومة. واتساقاً مع ذلك يجب أن نطور ونغيير ونجدد دائح) وألا يبقى التنظيم تقليدي. (19) 


\section{ت. تمكين العاملين}

تعني قدرة القائد على منح العامليّن سلطةً مؤقتةً، أو دوراً وظيفيّاً لإبداء آرائهم حول طبيعةٍ العمل، ويؤدي ذلك إلى جعلِهم قادرين على التأثيرِ على النتائج النهائيّة، التي سيتمٌ التوصل إليها بعد تطبيق أحد الآراء، وذلك من خلال تمكينِهِم من الحصول على استقلاليّنِهِم ضمن بيئة العمل، مع الحرص على أن يحافظَو اعلى تطور أدائهم، والاستفادةِ من خبراتهم لتحقيق الأهداف المطلوبة منهم. (20) ث. التوجه الإستراتيجي

يعتبر التوجه الإستراتيجي حجر الأساس لنجاح أي منظمة، حيث أنه المسار الذي تسترشد به المنظات في رحلتها إلى مستقبلها المنشود، إذ أصبحت من المهات الجوهرية للقائد الملهم لكي يدير أعماله بشكل إستراتيجي، لأنه يتعامل مع مستقبل غير مؤكد يتطلب منه اتخاذ قرارات إستراتيجية لضمان مستقبل المنظمة، فمن خلال توجهاتها تقوم المنظمة بوضع أهدافها الإستراتيجية، إذا أن التوجه الإستراتيجي يجعل الإدارة العليا في المنظمة تدرك تماماً ما هي غايتها وما هي مجالات نشاطاتها الخارجية، ومن هم المستفيدون من الخدمات التي تقدمها. (21)

\section{ثانيًا : الصراع التنظيمي}

\section{1 - مفهوم الصراع التنظيمي}

يعد الصراع إحدى الظواهر الطبيعية الموجودة في حياتنا أفرادا ومنظلات، وهو أمر حتمي، لأن الثبات والاستقرار يكاد يكون من الأمور المستحيلة، فالتغير مستمر ودائم في كل شيء، وهذا ما يفسر وجود الصراع التنظيمي في المنظلات كظاهرة طبيعية،(22) حيث يعبر عن الصرع في اللغة العربية بـ (النزاع أو الخصام أو الخلاف)، أما كلمة (Conflict) الإنكليزية فهي من اصل لاتيني وتعني عملية (الضرب أو الطرق أو العراك والمصادمة) إذن الصراع يدل على عدم الاتفاق أو النزاع أو التعارض والخلاف بين المصالح. ويعرف الصراع 
التنيمي بأنه العملية التي تسعى فيها وحدات نظام ما لتحقيق مصالحها على حساب مصالح وحدات أخرى. (23) قد عرَّف كل من (هودج وأنتوني Hodge \& Anthony) الصراع بأنه الموقف الذي تتعارض فيه الأهداف، الأفكار، الفلسفات، التوجهات بين اثنين أو أكثر من الأفراد أو الجماعات. بينما نظر أليه (مارس وسيمون (March \& Simon اختيار البديل الأفضل. وأكد (ورايت ونوي Wright \& Noe) على أنه الإدراك بأن القيم أو الأهداف أو الحاجات غير متوافقة. وكذلك عبر عنه (كويك ونيلسون Quick \& Nelson) بأنه آي موقف تقود فيه السلوكيات أو المشاعر او الاتجاهات او الأهداف المتنافرة إلى عدم الموافقة أو التعارض بين طرفين او أكثر. (24) يظهر مما تقدم ان التباين في المفاهيم هو ظاهرياً وليس جوهرياً، فالصراع هو تعبير شمولي عن الحالة أو الموقف الناشيء من عدم التوافق بين الأهداف، الفلسفات، الأيديولوجيات، القيم، الحاجات بين طرفين أو أكثر للحصول على المركز المتعارض المرغوب فيه من قبل هذه الأطراف. إذ يعد الصراع التنظيمي من اكبر التحديات التي تواجه إدارة المنظمات في الوقت الراهن. فرغم أنه قد يكون أمراً حتمياً ومرغوباً فيه أحياناً، وذلك عندما يساعد على تطوير وتحسين الأداء في المنظلات وزيادة فاعليتها، فإنه قد يكون غير مفيد وقد يؤدي إلى إعاقة تحقيق أهداف المنظمة في ظروف أخرى. ومن هنا يتطلب الأمر من الإدارات أن تكون على درجة عالية من الوعي الإداري لتتمكن من إدارة هذا الصراع بالشكل الذي يمكنها من تحقيق الأهداف، وأداء رسالة المنظمة بأكبر كفاءة مككنة. (25)

\section{2- مراحل الصراع التنظيهي}

أن الصراع عملية ديناميكية تنشأ وتتطور عبر مراحل متعاقبة، تبدأ بادراك الأفراد للاختلاف والتفاوت فيا بينهم سواء كان في الأهداف او المصالح او الحاجات والميول، ومن ثم تحليل هذه الاختلافات وبلورتها ليدخلو مرحلة الصراع العلني، حيث تتكون تكتلات معينة تمثل أطراف النزاع ويضع كل طرف استراتيجية 
للقضاء على الطرف الآخر. يمكن إن تطلق على هذه العملية بدورة حياة الصراع،(26) هناك عدة نماذج تبين هذه المراحل، وسيعتمد الباحثان على نموذج (لويس بوندي Louis Pondy) الذي يعد الأكثر قبو لاً وانتشاراً في هذا الصدد والذي يتكون من خمس مراحل وهي كالآتي: أ. مرحلة الصراع الخفي Latent Conflict: تتو افر في هذه المرحلة مسببات الصراع دون حدوثه. مثال ذلك المنافسة على الموارد، تباين في الأهداف والغايات، أو وجود تعارض أو تناقض وظيفي. وفي كل هذه الحالات لا يطفو الصراع إلى السطح نظرًا لانخفاض حدة الصراع أو عدم استعداد الطرفين لخوض عملية الصراع. (1) (n) ب.مرحلة الصراع المدرك Perceived Conflict: تبدأ هذه المرحلة عندما يدرك أطراف الصراع أن هناك صراعًا مرتقبًا سوف يحدث. وهنا يصبح الصراع مدركًا ولا يكون هناك مايستدعي بقائه حالة مستترة، وغالبًا ما يبدأ الطرف الذي يشعر أطراف الصراع بتناقض أو تضارب في المصالح والأهداف في هذه المرحلة. (27)

ت.مرحلة الشعور بالصراع (المحسوس) Felt Conflict: هذه المرحلة أكثر تقدمًا عن سابتتها وفيها يبدأ الأفراد بالشعور بالصراع بشكل واضح، وينشأ شعور انفعال عاطفي لدى اطراف الصراع، شعور شخصي وداخلي بالصراع مثل (القلق والتوتر والغضب)، ويصبح كل منهم طرفًا في الصراع ويسعى للفوز ولو على حساب الأهداف العامة للمنظمة. ث. مرحلة الصراع الظاهري (العلني) Manifest Conflict: وفي هذه المرحلة يلجأ الفرد أو الجماعة إلى انتهاج الأسلوب العلني الصريح، حيث يسعى كل طرف إلى إحباط خصمه من خلال عدم التعاون والتخريب و المشاحنات العلنية، وقد يأخذ أشكالًا أخرى مثل الانسحاب و اللامبالاة، وكل الوسائل الدفاعية الممكنة الأخرى، وبالتالي تصبح إمكانية العمل والتو اصل بين الافر اد صعبة بل مستحيلة مما يؤثر سلبًا على وروح العمل داخل المنظمة. (29) 
ج. مرحلة ما بعد الصراع العلني Conflict Aftermath: تعكس هذه المرحلة طبيعة العلاقة بين الأطراف المتصارعة بعد انتهاء الصراع، حيث يتم فيها تسوية الصراع وتحقيق التغييرات الضرورية، وهنا يظهر دور المنظمة جليًا في وضع حلول للصراع من خلال التعرف على جذور المشكلة وحلها، وإذا لم يتم التوصل إلى اتفاق مرضٍِ بحيث يقر أحد الأطراف بأنه الخاسر فسيكون هناك جولة جديدة محتملة من الصدامات

المكثفة. (30)

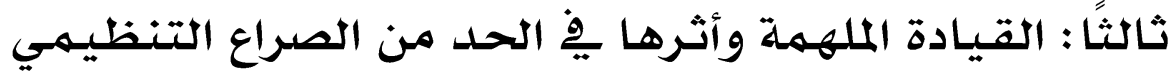
تعد القيادة الملهمة المحرك الأساس لعلاقة الرئيس بالمرؤوسين، إذ لها دور رئيس في ممارسة التأثير على العاملين للتعاون فيها بينهم من اجل تحقيق الأهداف التي تسعى المنظمة جاهدة لتحقيقها والمتمثلة في البقاء، والنمو، والاستمرار، وهي من الأنحاط التقليدية في القيادة الإدارية المبنية على تبادل المنافع بين القائد والمرؤوسين. فالحصول على المكافأة من القائد يقابله زيادة في الإنتاج، لهذا تعتبر عملية القيادة من أكثر العمليات تاثيرًا على لي السلوك التنظيمي، فهي تؤثر على دافعية الأفر اد للأداء، واتجاهاتهم النفسية ورضاهم عن العمل، وكذلك تعد أبعاد القيادة الملهمة محورًا رئيسيًا للعلاقة بين الرؤساء والمرؤوسين، ومما لاشك فيه أن كفاءة المنظمة تستمد من كفاءة الإدارة العليا فيها، حيث تظهر كفائتها بشكل واضح عندما تتعرض تلك الإدارة للمواقف الحرجة، والتي منها الضغوط والصراع التنظيمي، وأيضا كيفية أدارة الضغوط والصراعات بطريقة فعالة يعد أحد المحددات الرئيسية لكفاءة الإدارة العليا.(31) تظهر العديد من الدراسات انه كلم) كان نمط القيادة مختلفة في جميع أنشطة وسياسات وإجراءات المنظمة فأن ذلك يؤدي إلى نتائج مرغوب فيها من خلال أتباع عناصر وسمات شخصية متوفرة لدى القائد الملهم تساعده على إدارة المنظمة وعامليها بصورة تتناسب مع متطلبات المنظمة من تحقيق الأهداف المرجوة، حيث أن هناك بجموعة من العوامل التي تؤدي إلى زيادة فاعلية القائد في الحد من الصراع التنظيمي وهي كالآتي: 
أ. تكامل القدرات العقلية: يتمثل في مستوى معين من الذكاء والقدرة على الاستيعاب السريع والاسترجاع وحسن إدارة الوقت وعدم الاستغراق في التفاصيل. ب. الثبات الانفعالي: القدرة على التحكم في الغرائز بدرجة تتفق مع طبيعة الموقف وكذلك القدرة على تحديد المسافة النفسية في العلاقات الشخصية. ت.النضج الاجتحاعي: أي عدم المحاباة والقدرة على تكوين علاقات اجتماعية طيبة والتعامل مع المرؤوسين على أسس واضحة المعالم خالية من العقد النفسية. ث.وجود مهارات فنية عالية: يجب أن تتو افر لدى القائد الخبرة الفنية التي تفوق تابعيه ويكون لدية القدرة على حل المشكلات الفنية التي تواجهُم ويعمل دائم) للسعي نحو تنمية كو ادر فنية جديدة. كذلك من العوامل التي تزيد مهارات القيادة الفعالة في الحد من الصراع التنظيمي هي ما يلي: أ. الشخصية السوية المرنة القادرة على التعامل في جميع المواقف. ب. مهار ات الأداء والتي يطلق عليها وظائف المدير وهي التخطيط، التنظيم، التوجيه، والرقابة. ت. التوجهات المستقبلية من النواحي التكنولوجية، الاستراتيجية، المعلوماتية، التسويقية، البشرية، والمعرفة بالتحو لات العالمية.

ث. المهارات الإبداعية لحل المشكلات الحالية والمتوقعة، التحديث و التطوير، والبحوث والابتكار. ج. المهارات السلوكية في التعامل مع الجميع والتي تتضمن مهارات الاتصالات، المشاركة، الفاعلية، الدافعية والتحفيز، إدارة الوقت والاجتحاعات، إدارة الصراعات، التفاوض البناء، والتغيير الإنساني. ح. المهارات الوظيفية والتي تتضمن تخطيط القوى العاملة وتوظيفها وتسكينها، التدريب و التنمية، المتابعة وتقييم الأداء، الأجور والرواتب وما في حكمها، والترقي. (32) ختامًا يمكن القول أن الصراع التنظيمي يتأثر بأسلوب القيادة المعتمد، فعندما تعتمد المنظمة على أسلوب القيادة الملهمة المرتكزة على وجود قائد إداري بعقلية متفتحة قادرة على إحداث التغيير في المنظمة من خلال عدة عناصر منها؛ التطبيق الجيد لقيم ومبادئ الإدارة والتنظيم، المشاركة في اتخاذ القرارات، إعادة تصميم 
الهيكل التنظيمي، تحديد الأسباب الحقيقية للصراع، وأخيرًا الأنشطة العلاجية في مناخ العمل، فإن هذه العناصر تؤثر إيجابًا في الحد من الصراع التنظيمي داخل المنظمة.

المبـحث الثاني: الدراسة الميدانية (نتائج التحليل الإحصائي) أولاً: تحليل خصائص المتغيرات الديموغرافية

جدول رقم (4) خصائص المتغيرات الديموغرافية

\begin{tabular}{|c|c|c|c|c|c|c|c|}
\hline \multicolumn{2}{|c|}{ التكرارات } & الفئات & الخاصية & \multicolumn{2}{|c|}{ التكرارات } & الفئات & الخاصية \\
\hline$\% 21$ & 44 & كلية العلوم الاسلامية & & $\% 87$ & 183 & ذكر & \\
\hline$\% 19$ & 40 & كلية الاداب & & $\% 13$ & 27 & انثى & 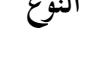 \\
\hline$\% 15$ & 32 & كلية الزبية للبنات & & $\% 10$ & 21 & 30 & \\
\hline$\% 11$ & 23 & كلية الزبية الطارمية & & $\% 28$ & 59 & 30 لأقل من 40 سنة & \\
\hline$\% 9$ & 19 & كلية الادارة والاقتصاد & الكلية & $\% 36$ & 76 & 40 لأقل من 50 سنة & العمية ل العمية \\
\hline$\% 7$ & 15 & كلية القانون & & $\% 18$ & 38 & 50 لأقل من 60 سنة & \\
\hline$\% 2$ & 4 & كلية الاعلام & & $\% 8$ & 16 & من 60 سنة فأكثر & \\
\hline$\% 10$ & 21 & كلية الطب & & $\% 34$ & 71 & 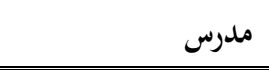 & \\
\hline$\% 8$ & 8 & كلية المندسة & & $\% 44$ & 92 & استاذ مساعد & (1) \\
\hline$\% 2$ & 4 & كلية طب الاسنان & & $\% 22$ & 47 & استاذ & \\
\hline
\end{tabular}

يتضح من الجدول السابق ان نسبة الذكور أعلى من نسبة الاناث حيث تصل الى 87٪ وبالتأكيد نجد ان الرجال يتعاملو مع الصراع التنظيمي بشكل يختلف عن تعامل الاناث معه، نظرا لاختلاف طبيعة الشخصية بينه|، فالاناث يفضلن تجنب الصراعات التنظيمية.

بالنظر الى الجلدول نجد ان معظم أفراد العينة يقعوا فى الفئة العمرية من 40 لاقل من 50 سنة بنسبة 36٪ ، يليها الفئة العمرية من 30 لاقل من 40 سنة بنسبة 28٪ ، إذ اوضحت الدراسات السابقة ان الفرد كلما زاد 
عمره زاد نضجه وقدرته على مواجهة التحديات والقدرة على حل الصراعات بشكل عقلاني وهذا يعنى ان معظم افر اد العينة يتمتعون بقدرتهم على التعامل مع الصراعات التنظيمية داخل الجامعة.

كما يتبين من الجمدول ان معظم افراد العينة حاصلين على درجة استاذ مساعد حيث تصل نسبتهم الى 44\% ، وهذا يؤكد ما توصلنا اليه من قبل وهو وصول افراد العينة الى درجة عقلانية كافية لمواجهة الصراعات التنظية. ونظرا لان كلية العلوم الاسلامية وكلية الاداب من اقدم الكليات داخل الجامعة العراقية وعدد العاملين بها مرتفع نسبيا مقارنة بباقي كليات الجامعة، إذ نجد ان اغلب افراد العينة يقومون بالتدريس بكلية العلوم الاسلامية حيث تصل نسبتهم الى 44٪ ، تليها كلية الاداب حيث تصل نسبتهم الى 40٪.

ثانيًا : تحليل الخصائص الوصفية لمتغيرات الدراسلة 1 1. المتغير المستقل (الثقة بالنفس، إدارة التغيير، تمكين العاملين، والتوجه الاستراتيجي). جدول رقم (5) التحليل الوصفي لفقرات المتغير المستقل "للقيادة الملهمة"

\begin{tabular}{|c|c|c|c|c|}
\hline 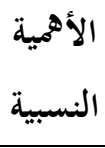 & 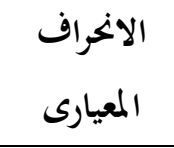 & 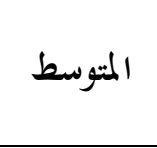 & 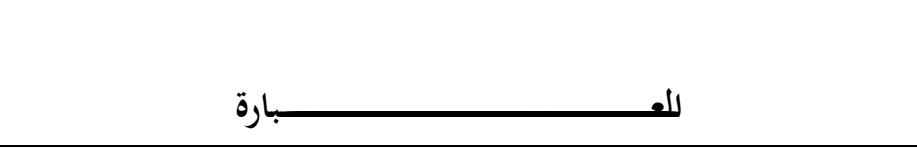 &  \\
\hline \multicolumn{5}{|c|}{ البعد الأول " الثقة لنفس" } \\
\hline 2 & 1.18240 & 3.5381 & تساعد القائد في التغلب على المشاكل التي يتعرض لها اعضاء الهيئة & 1 \\
\hline 1 & 1.12820 & 3.5476 & تزرع الثقة لدى اعضاء الهيئة التدريسية لتطوير العمل نفسهم & 2 \\
\hline 3 & 1.17372 & 2.9810 & تساعد اعضاء هيئة الثدريس في اتخاذ القرارات الملائمة في الوقت & 3 \\
\hline 4 & 1.12981 & 2.8762 & تساهم اعضاء الهيئة التدريسية في تقبل النقد البناء أثناء العمل. & 4 \\
\hline 5 & 1.14136 & 2.8667 & تساعد في تحقيق طموحات اعضاء هيئة التدريس لجامعة. & 5 \\
\hline - & 1.15109 & 3.1619 & \multicolumn{2}{|l|}{ 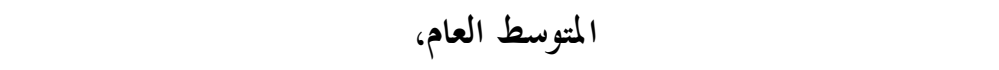 } \\
\hline \multicolumn{5}{|c|}{ 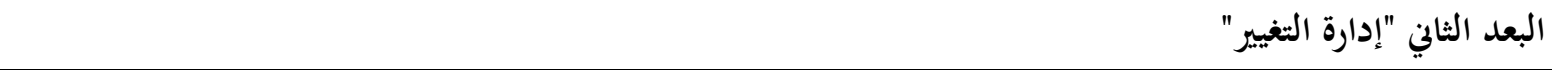 } \\
\hline 1 & 1.18992 & 3.2190 & يشاركة اعضاء الميئة التدريسية في صياغة الؤية المستقبلية للعمل & 6 \\
\hline
\end{tabular}




\begin{tabular}{|c|c|c|c|c|}
\hline 5 & 1.32030 & 2.6714 & يراعي المسئول توفر المرونة عند اجراء تخطيط المسبق لإدارة التغيير & 7 \\
\hline 3 & 1.15951 & 2.9952 & الكلع الثخص المسئول الخطط السنوية للتغيير والتي تغطي جميع & 8 \\
\hline 4 & 1.15848 & 2.6952 & للتغيير · ل & 9 \\
\hline 2 & 1.04098 & 3.1762 & يتم كتيئة الجحو الملائم لدعم مشاركة اعضاء هيئة التدريس في التغيير & 10 \\
\hline 6 & 1.01374 & 1.9238 & | يتم تقديم المكافأت المالية للمشاركين في دعم عملية التغيير. & $\mathbf{1}^{1}$ \\
\hline- & 1.14715 & 2.7799 & \multicolumn{2}{|l|}{ 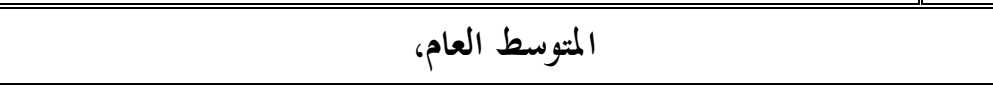 } \\
\hline \multicolumn{5}{|c|}{ 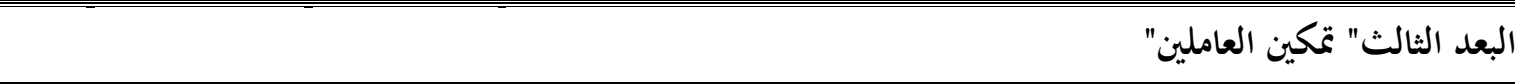 } \\
\hline 1 & .96623 & 4.0524 & تقوم القيادات لكلية بتفويضي السلطات الكافية لإنجاز مهام عملي & 12 \\
\hline 4 & 1.09375 & 3.1190 & | يتم توفير وسائل الاتصال الفعالة والمتطورة. & 13 \\
\hline 3 & 1.15436 & 3.5000 & تتسم التعليمات الصادرة للعمل لوضوح. & 14 \\
\hline 6 & 1.15951 & 2.8048 & يتوفر لاعضاء هيئة التدريس فرص لنطوير مهاراتم في مجال عملهم & 15 \\
\hline 5 & 1.14484 & 2.9286 & يتم منح المرونة الملائمة للتصرف في أداء المهام الموكلة اليك. & 16 \\
\hline 2 & 1.06436 & 4.0333 & يشعر اعضاء الهيئة التدريسية ن الامتيازات الممنوحة لهم متساوية & 17 \\
\hline- & 1.09717 & 3.4063 & \multicolumn{2}{|l|}{ المتوسط العام، } \\
\hline \multicolumn{5}{|c|}{ البعد الرابع " التوجه الاستزاتيجي " } \\
\hline 4 & 1.32030 & 2.6714 & تقوم الجحامعة بصياغة الحطة الاستزاتيجية الحخاصة بما بدقة عالية. & 18 \\
\hline 2 & 1.12820 & 3.5476 & الاستزاتيجيات التي تعتمدها الجحامعة تتلائم مع المتغيرات البيئة الخيطة. & 19 \\
\hline 1 & .96623 & 4.1524 & يتبع سياسة واضحة من وجهة نظر اعضاء الهيئة التدريسية لجامعة & 20 \\
\hline 3 & 1.13764 & 3.3048 & يشكل لجحان خاصة داخلية لجامعة لصياغة الحطة الاستزاتيجية. & 21 \\
\hline - & 1.13809 & 3.4190 & 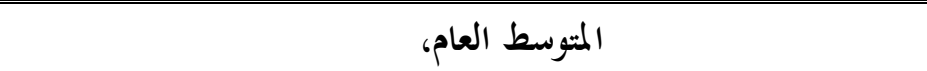 & \\
\hline
\end{tabular}

نلاحظ من الجمدول رقم (5) الذي يمثل التحليل الوصفي للمتغير المستقل القيادة الملهمة أنه تضمن على (21) عبارة، وكان المتوسط العام لإجابات افراد العينة مرتفعًا حيث بلغ على 3.17، و انحراف معياري قدره 
1.13، وقد نالت العبارة رقم (20) التابعة للبعد الرابع التوجيه الاستراتيجي، والتي تقول (يتبع سياسة واضحة من وجهة نظر اعضاء الهيئة التدريسية بالجامعة) على المرتبة الاولى فى إجابات افراد العينة بمتوسط قدره 15.15، وانحراف معياري 0.9 0. في حين جاءت العبارة رقم (12 ) الخاصة ببعد تمكين العاملين والتي تنص على (تقوم القيادات بالكلية بتفويضي السلطات الكافية لإنجاز مهام عملي) على المرتبة الثانية بمتوسط

$$
\text { 0.9 } 0.96 \text { 4.05، وانحر اف معياري }
$$

2. المتغير التابع (إدارة الصراع التنظيمي).

جدول رقم (6 ) التحليل الوصفي لفقرات المتغير التابع "الصراع التنظيمي"

\begin{tabular}{|c|c|c|c|c|}
\hline ترتيب & 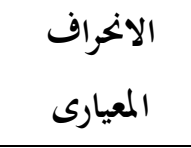 & 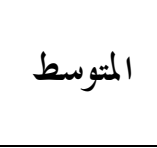 &  & الرقم \\
\hline 6 & 1.01617 & 3.5571 & يوجد تداخل فى المهام المراد تنفيذها من قبل أعضاء الميئة التدريسية & 1 \\
\hline 1 & .84507 & 4.1143 & تدلي مستوى التعاون بين أعضاء الهيئة الثدريسية داخل الجامعة. & 2 \\
\hline 2 & .98220 & 3.9190 & يوجد تنافس ضار وسلبي بين أعضاء الهيئة التدريسية بجامعة العراقية. & 3 \\
\hline 5 & 1.15545 & 3.6286 & المهام موزعة بشكل غير متكافئ مما يتسبب فل حدوث صراعات. & 4 \\
\hline 4 & 1.04818 & 3.6524 & يما ينم الخا عن لبعض الأفراد على حساب أشخاص آخرين فل الامتيازات & 5 \\
\hline 8 & 1.05018 & 3.5000 & ينتشر مفهوم الشلة بين الافراد مما ينبع عنه حدوث صراع. & 6 \\
\hline 3 & 1.04194 & 3.9000 & اعجموعة آخرى عمل مجما ينتج عنه مدو اعضاء الميئة التدريسية على نتائج عمل & 7 \\
\hline 7 & 1.06823 & 3.5048 & تكله صراع أحد اعضاء الهيئة الثدريسية عمال ليست من مهامه مما ينتج & 8 \\
\hline- & 1.02592 & 3.7220 & المتوسط العام، & \\
\hline
\end{tabular}

نلاحظ من الجدول رقم (6) الذي يمثل التحليل الوصفي للمتغير التابع الصراع التنظيمي، أنه تضمن على (8) عبارات، و كان المتو سط العام لإجابات افراد العينة مرتفع حيث بلغ على 3.72، و انحر اف معياري قدره 1.02، وقد نالت العبارة رقم (2) والتي تقول (تدني مستوى التعاون بين أعضاء هيئة التدريس داخل 
الجامعة) على المرتبة الاولى حيث حصلت إجابات افراد العينة على متوسط قدره 4.11، وانحراف معياري

$$
\begin{aligned}
& \text { ثالثًا : تحليل الانحسدار المتعدد لاختبـار فرضيات الدراسـة } \\
& \text { جدول (7) نتائج تحليل الانحدار المتعدد }
\end{aligned}
$$

\begin{tabular}{|c|c|c|c|c|c|c|c|}
\hline Model & $\begin{array}{c}\text { R } \\
\text { معامل الارتباط }\end{array}$ & $\begin{array}{l}\text { R Square } \\
\text { مربع معامل الارتباط }\end{array}$ & \multicolumn{2}{|c|}{$\begin{array}{l}\text { Adjusted R Square } \\
\text { مربع معامل الارتباط المعدل }\end{array}$} & \multicolumn{3}{|c|}{$\begin{array}{l}\text { Std. Error of the } \\
\text { Estimate } \\
\text { الخطأ المعياري في التقدير }\end{array}$} \\
\hline 1 & .511 & .262 & \multicolumn{2}{|c|}{.247} & \multicolumn{3}{|c|}{5.13392} \\
\hline \multicolumn{8}{|c|}{ ANOVA } \\
\hline \multicolumn{2}{|c|}{ Model } & Sum of Squares & df & \multicolumn{2}{|c|}{ Mean Square } & $F$ & Sig. \\
\hline \multirow{3}{*}{1} & $\begin{array}{r}\text { Regressio } \\
\mathbf{n}\end{array}$ & 1913.278 & 4 & \multicolumn{2}{|c|}{478.320} & 18.148 & .000 \\
\hline & Residual & 5403.203 & 205 & \multicolumn{2}{|c|}{26.357} & & \\
\hline & Total & 7316.481 & 209 & & & & \\
\hline
\end{tabular}

يوضح الجمدول السابق معامل ارتباط بيرسون بين المتغير التابع والمتغير المستقل، حيث بلغت قيمة متوسطة قدرها (11 0.51 )، وقيمة مربع معامل الارتباط (0.262)، الذي يوضح مدى البيانات المستخدمة بالمتغيرات المستقلة في تقدير المتغير التابع، وقيمة مربع معامل الارتباط المعدل (0.247)، نجد النموذج المقدر يعبر عن أربعة ابعاد المتغير المستقل معا بقيمة 26.2\% من البيانات وهذه نسبة منخفضة فكلم) ارتفعت القيمة كلم) دل على مدى ملائمة النموذج فى التفسير. وبالنظر الى قيمة خطأ التقدير وهو منخفضة كلما دل على خطأ اقل بالنموذج. يتضح من جدول السابق نتائج تحليل ANOVA لاختبار معنوية الانحدار، ونجد أن قيمة (00.=.sig)، وهي اقل من مستوى المعنوية (5 0 ) ـ اي أن الانحدار معنوي وبالتالي يوجد تأثير من المتغيرات المستقلة على المتغير التابع، لذا سوف نرفض فرضية العدم ونقبل الفرضية البديلة التي توضح انه يوجد تأثير ذو دلالة إحصائية 
لعناصر القيادة الملهمة وهي: إدارة التغيير، الثقة بالنفس، تمكين العاملين، التوجه الاستراتيجي، على الصراع التنظيمي لاعضاء الهيئة التدريسية بالجامعة العراقية.

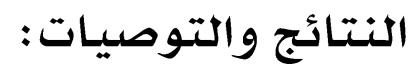

النتـائج :

تتضمن هذه الفقرة مناقشة النتائج التي توصل إليها الباحثان من خلال تحليل بيانات الدراسة، وعلى وفق نتائج التحليل الإحصائي تم وضع عدد من الاستناجات التطبيقية المتعلقة بمتغيرات الدراسة، وكما يأتي: 1. بينت نتائج التحليل الإحصائي أن اتجاهات المبحوثين نحو أبعاد القيادة الملهمة (الثقة بالنفس، إدارة التغيير، تمكين العاملين، والتوجه الاستراتيجي)، كانت كلها إيجابية، حيث بلغ المتوسط العام لهذا الابعاد وبالترتيب (3.161، 2.779، 3.406، 3.419)، 3.4 ما يشير إلى تمتع القيادة في الجامعة المبحوثة بالسمات الكارزماتية التي تمكنهم من التأثير في مرؤوسيهم، وإثارة روح التحدي لديهم لتوجيهم نحو تحقيق الأهداف.

2. بينت نتائج التحليل الإحصائي أن الجاهات المبحوثين نحو متغير الصراع التنظيمي كانت مرتفعة، حيث بلغ المتوسط العام لهذا المتغير (3.722)، وهو ما يشير ربحا إلى عدم راحة واستقرار أعضاء الهيئة التدريسية في العمل داخل الجامعة، ما يوثر بدوره على كفاءتهم وادائهم، وبالتالي قد يؤدي الى عدم رغبتهم في المحافظة على عضويتهم واستمر ارهم في الجامعة، والتفكير بترك العمل والانتقال إلى جامعة أخرى. 3. هناك مستويات مرتفعة نوعًا ما لتوفر أبعاد القيادة الملهمة لدى أعضاء الهيئة التدريسية بالجامعة العراقية، و اكثر هذه الأبعاد تو افرًا من حيث المستوى هو التوجه الاستراتيجي، حيث كان المتوسط العام للوسط الحسابي لمجمل عباراته (3.419)، وهو الأعلى مقارنة ببقية الابعاد، حيث حققت الفقرة المتعلقة بـ (يتبع سياسة واضحة من وجهة نظر اعضاء الهيئة التدريسية بالجامعة) على القيمة الأعلى 
بمتوسط قدره (4.15)، بينما حققت الفقرة المتلعقة بـ (تقوم الجلامعة بصياغة الخطة الاستراتيجية

الخاصة بها بدقة عالية)، على أقل قيمة من بين الفقرات بمتوسط قدره (1 2.67 ). 4. وجود تاثير ذي دلالة إحصائية لأبعاد القيادة الملهمة وهي: الثقة بالنفس، إدارة التغيير، تمكين العاملين، و التوجه الاستراتيجي، في الحد من أسباب الصراع التنظيمي بين أعضاء الميئة التدريسية في الجامعة العراقية.

5. تبين فقرات التحليل الوصفي لمتغير الصراع التنظيمي أن أكثر ما يؤدي إلى حدوث الصراع التنظيمي بين أعضاء الهيئة التدريسية في الجامعة العراقية هو تدني مستوى التعاون فيما بينهم، والتي تمثلت بالفقرة الثانية بمتوسط حسابي قدره (4.11)، وهو ما يعد مرتفعًا نسبيًا.

\section{التوصيات}

في ضوء ما تقدم من الدراسة النظرية والميدانية والنتائج التي تم التوصل إليها، يمكن تقديم التوصيات التالية: 1. ضرورة أن تقوي إدارة الجامعة والمتمثلة برئيسها علاقتها بأعضاء الهيئة التدريسية من خلال اجراء لقاءات دورية خلال العام الدراسي للتعرف على مشاكلهم ومقترحاتهم وكل ما يخص العملية التعليمية، وأيضًا مشاركتهم بالآراء الخاصة باتحاذ القرارات، الأمر الذي من شأنه أن يفيد الإدارة بأفكار جديدة، وكذلك إشعار أعضاء هيئة التدريس بقيمتهم العالية، مما يعزز روح الثقة والرضا عندهم، ويمكنهم من أداء واجباتهم بالشكل المطلوب. وهذه التوصية تنطبق أيضًا على السادة عمداء الكليات وتكون اللقاءات بشكل جمعي وانفرادي.

2. يجب على إدارة الجامعة أن تسعى لتنمية أبعاد القيادة الملهمة لدى القيادات الأكاديمية في الكليات والأقسام العلمية، لما لها من تأثير مباشر في الحد من الأسباب التي تؤدي إلى حدوث الصراع التنظيمي، وذلك بتعزيز الثقة والتعاون بين القيادات الأكاديمية للكليات والأقسام وأعضاء الهيئة التدريسية، ويمكن أن يكون ذلك من خلال عقد لقاءات اجتماعية غير رسمية، او عقد ندوات حوارية بناءه بينهم

$$
\text { بعيدًا عن الأطر الرسمية. }
$$


3. ضرورة التركيز على فقرتي عدم التعاون بين أعضاء الهيئة التدريسية والتنافس الضار والسلبي بينهم داخل الجامعة، بصفتها من اكثر الأسباب التي تؤدي الى حدوث الصراع التنظيمي في الجامعة، وذلك بمراجعة السياسات المتعلقة بتوزيع المسؤوليات بين أعضاء الهيئة التدريسية في الكليات والأقسام العلمية. مما يخفف من حدة تأثير هذين السبين في حدوث الصراعات التنظيمية. 4. يجب على إدارة الجامعة التركيز على الأسباب الأخرى المؤدية لحدوث الصراع التنظيمي، ومحاولة تخفيفها في الكليات والأقسام العلمية، وذلك من خلال إعادة النظر بها يتعلق بتفويض الصلاحيات الممنوحة، ووضع حدود فاصلة للمسؤوليات، مما يجعلها واضحة لجميع الأطراف، وكذلك تحديد الأهداف بشكل واضح خاصة لأعضاء الهيئة التدريسية حتى لا يكون هنالك أي تعارض أو سوء فهم. 5. أن من أحد أسباب الصراع هو المحاباة لبعض الأفراد على حساب الآخرين، لذلك يتوجب على إدارة الجامعة والقيادات الأكاديمية للكليات والأقسام تعزيز مبدأ العدالة والمساواة بين اعضاء الهيئة التدريسية في كافة الأمور التي تتم بينهم من ترقيات وحو افز مادية ومعنوية وغيرها دون أي تمييز بينهم.

\section{الههوامش:}

(1) سهاد برقي كامل وآخرون، القيادة الملهمة ودورها في تحقيق التميز التنظيمي دراسة إستطلاعية في المدارس الإعدادية الحكومية في مدينة

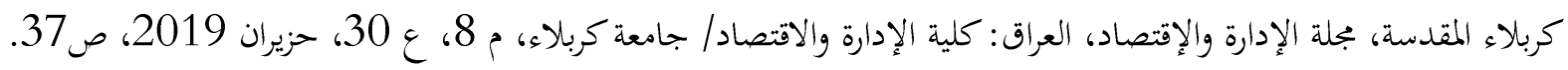

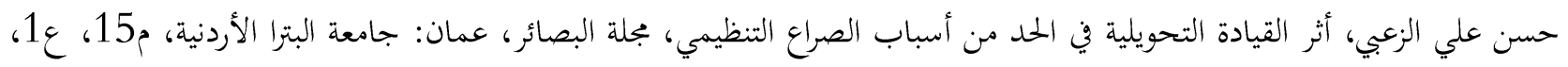

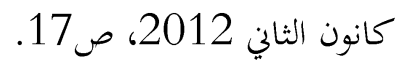

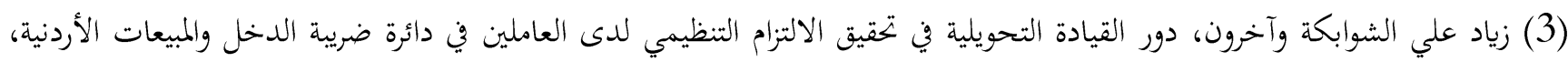

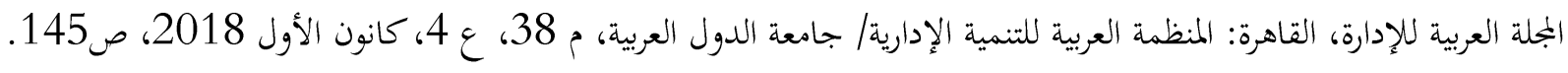



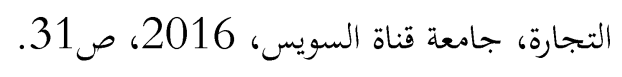

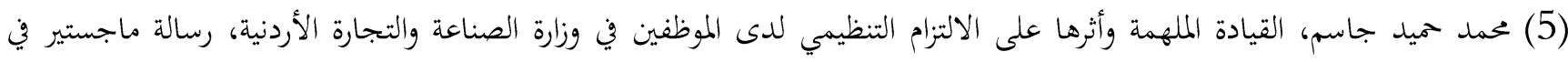

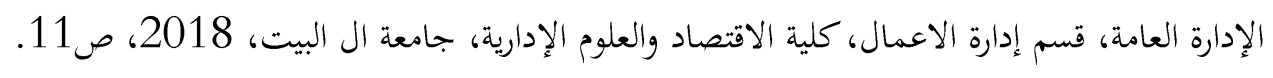

Ivancevich. J.H. \& Mattevson M.T., Organization Behavior \& Management, Boston, Mass: McGraw-Hill, (6) 6th edn, 2002, Pp55. 


$$
\text { (7) سهاد برقي كامل وآخرون، مرجع سابق ذكره، ص43) }
$$

David A. Waldman, et al, Leadership and Neuroscience: Can We Revolutionize the Way That Inspirational (8) Leaders Are Identified and Developed? Journal the Academy of Management Perspectives, USA: February 2011, Pp 61.

Thomas Patrick, Inspirational Leadership: The Five Essential Elements, UK: House Linchpin. Rochester, (9) 2010, Pp27.

Judith Leary-Joyce, inspirational manager: How to build relationships that deliver results, Pearson: Prentice

Hall Business, 1st 2009, Pp3.

Jerald Greenberg \& Robert Baron, Behavior in organization, Prentice Hall, NJ, 8th edn, 2004, Pp59.

$$
\begin{aligned}
& \text { 18 18مد حميد جاسم، مرجع سابق ذكره، ص6. } \\
& \text { يمكن الرجوع الى المراجع الاتية: }
\end{aligned}
$$

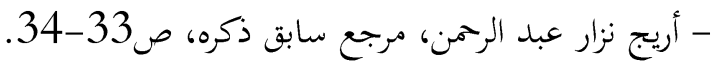

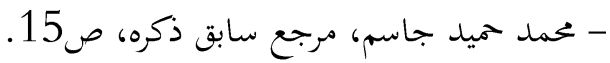

Aparna Joshi. et al, Getting Everyone on Board: The Role of Inspirational Leadership in Geographically -

Dispersed Teams, Organization Science, Vol.20, No.1, January-February 2009, Pp242-244

(14) سلطان احمد خليف، وزيرة يهيى محمد، القيادة الملهمة والمفاجأة الإستراتيجية دراسة استطلاعية لأراء عينة من القيادات الإدارية في عدد

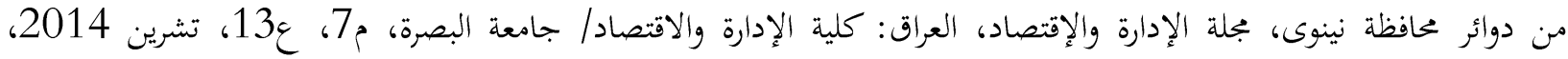

$$
\text { 15) محمد حميد جاسم، مرجع سابق ذكره، ص20. }
$$

(16) بسام سمير الرميدي، أثر تطبيق نمطي القيادة الموزعة والقيادة الملهمة على التهكم التنظيمي: دراسة تطبيقية على شركات السياحة

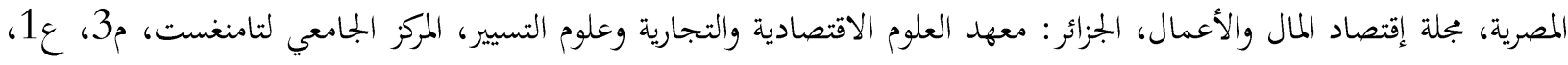

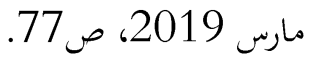

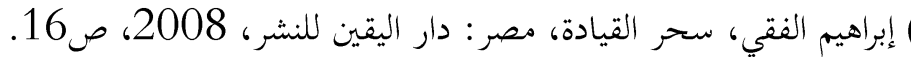

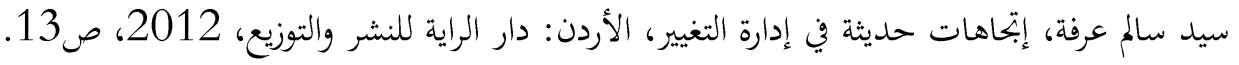

$$
\begin{aligned}
& \text { إبراهيم الفقي، مرجع سابق ذكره، ص28. }
\end{aligned}
$$

(20) سامي وفيق صالح، أثر القيادة الملهمة في إدارة الأزمات: دراسة تطبيقية على وزارة الصحة الفلسطينية، المجلة العلمية للاقتصاد والتجارة،

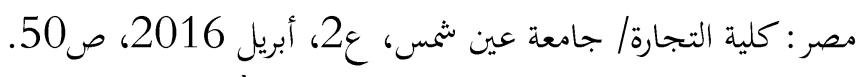

(21) محمود سمير الحلبي، دور القيادة الملهمة في توظيف مخرجات البحث العلمي في وزارة الداخلية والأمن الوطني الفلسطيني، رسالة ماجستير

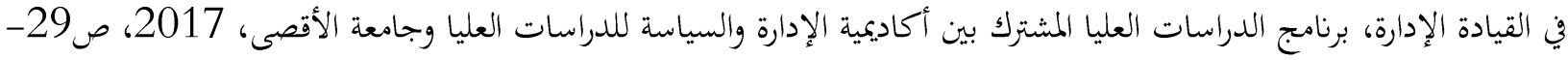

(22) موسى اللوزي، التطوير التنظيمي 'اساسيات ومفاهيم حديثة'، عمان: دار وائل للطباعة والنشر والتوزيع، 2003، ص74. 
(23) مؤمن خلف عبد الواحد، الأساليب المتبعة في إدارة الصراع التنظيمي داخل المنظمات غير المكومية في قطاع غزة من وجهة نظر

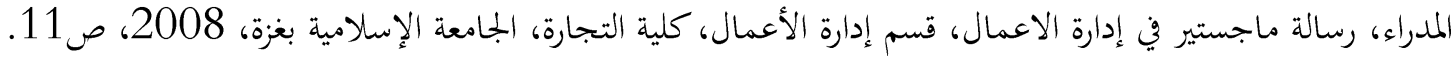

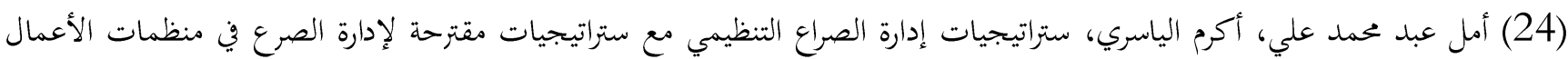

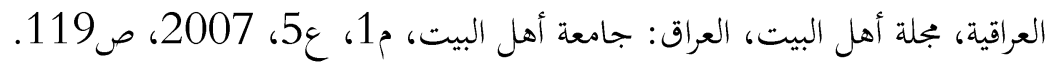

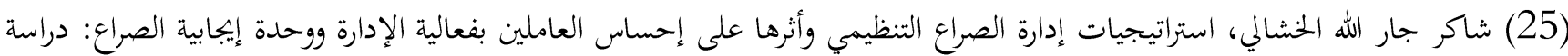

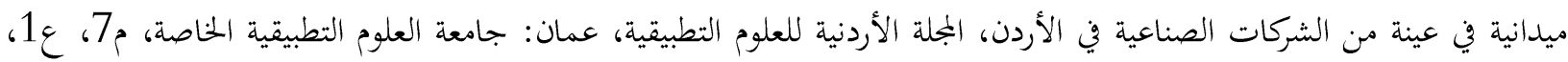

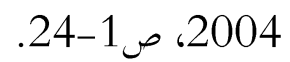

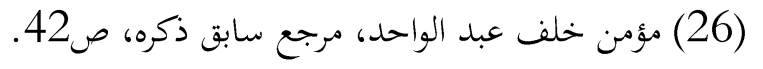

(27) عادل محمد زايد، تكوين الفرق والعمل الجماعي، ضمن مشروع الطرق المؤدية إلى التعليم العالي، القاهرة: مركز تطوير الدراسات العليا

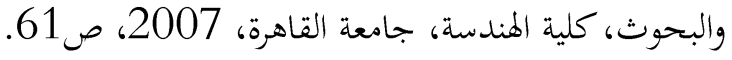

(28) حسين حريم، إدارة المنظمات منظور كلي، عمان: دار حامد، 2010، طاندة 2010، ص244.

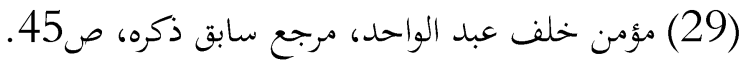

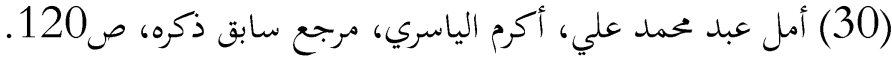

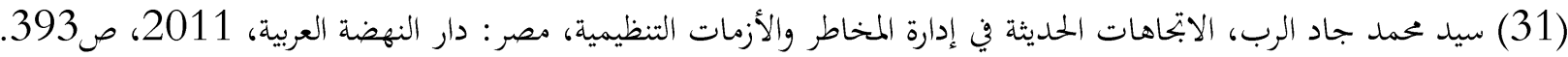

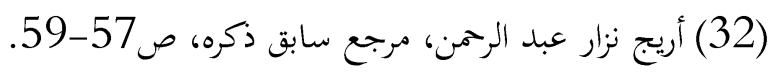

